Religare, ISSN: 19826605, v.16, n.2, dezembro de 2019, p.659-691

\title{
Meditação e yoga nas camadas médias do Rio de Janeiro: análise do campo nos estudos da Bhagavad Gita
}

\author{
Meditation and yoga in Rio de Janeiro's middle class: fieldwork \\ analysis in the studies of the Bhagavad Gita
}

Cecilia Bastos ${ }^{1}$

\section{Resumo}

Este artigo retrata o trabalho de campo de aproximadamente dez anos de convívio com um grupo de estudantes de Vedanta do Rio de Janeiro. Ao participar das aulas do curso "Bhagavad Gita", principal texto ensinado em Vedanta, verifiquei como os alunos percebem e vivenciam a prática da meditação, $\mathrm{O}$ "Eu" consciência e seu papel (dharma) no mundo. Também observei o que significa, para eles, a obtenção de um "distanciamento" de si e de um "comando" sobre a mente. Além disso, pesquisei de que maneira eles entendem os conceitos de felicidade, sofrimento e yoga e, ainda, como idealizam se tornar yogis, não no sentido de como vivem, mas do tipo de mente que possuem.

Palavras-chave: Meditação; Vedanta; Yoga; Bhagavad Gita; Espiritualidade.

\section{Abstract}

This article portrays the fieldwork of approximately ten years of interaction with a group of Vedanta students from Rio de Janeiro. By attending classes of the Bhagavad Gita course, the main studied text in Vedanta, I've looked at how the students perceive and experience the practice of meditation, the " $\mathrm{I}$ " consciousness and their role (dharma) in the world. I've also observed what it means for them to attain a "detachment" from themselves and a "command" over the mind. In addition, I've researched ways in which they understand the concepts of happiness, suffering and yoga, and how they idealize to become yogis, not in the sense of how they live, but in the kind of mind they possess.

Keywords: Meditation; Vedanta; Yoga. Bhagavad Gita; Spirituality.

\footnotetext{
${ }_{1}$ Pesquisadora do Programa de Pós-graduação em Antropologia Social do Museu Nacional/UFRJ. Doutora em Ciências Sociais pelo Programa de Pós-Graduação em Ciências Sociais da UERJ. E-mail: ceciliagbastos@gmail.com
} 
Religare, ISSN: 19826605, v.16, n.2, dezembro de 2019, p.659-691

\section{Introdução}

Este artigo faz parte do trabalho de campo realizado durante o doutorado ${ }^{2}$ em ciências sociais na UERJ (PPCIS) e também durante a continuação deste campo no pós-doutorado em antropologia social no Museu Nacional (PPGAS/UFRJ). ${ }^{3}$ A questão principal é entender os significados da devoção de um grupo de estudantes de Vedanta do Rio de Janeiro. Este grupo de alunos consiste de estudantes universitários, aposentados, psicólogos, cineastas, engenheiros, chefs de cozinha, empresários, astrólogos, biólogos, terapeutas, tradutores, filósofos, escritores, dermatologistas, professores universitários, designers, entre outros, sendo grande a presença de professores de yoga e meditação. Entendo que estejam inseridos nos contextos das camadas médias urbanas da sociedade brasileira pelo fato de quase todos possuírem curso superior completo ou em andamento e também por grande parte do grupo já ter realizado ao menos uma viagem à Índia com o intuito de aperfeiçoamento nas técnicas de yoga e meditação ou aprofundamento do aprendizado de Vedanta; para este último objetivo, viver alguns meses ou anos em um ashram foi fundamental para vivenciar e assimilar o ensinamento enquanto imerso na cultura indiana.

A fim de entender melhor as ações e representações dos alunos sobre o sentido atribuído à devoção, foi fundamental, através da observação participante, fazer parte desse grupo como estudante do curso da Bhagavad Gita, entre outros cursos de Vedanta.

\footnotetext{
2 Ver: Bastos (2016a).
}

3 Para detalhes a respeito do trabalho de campo na Índia e no Vidya Mandir, a pesquisa sobre devoção com os vedantinos e as metodologias e conceitos utilizados, ver: Bastos (2016b; 2016c; 2017a; 2017b, 2018). 
Religare, ISSN: 19826605, v.16, n.2, dezembro de 2019, p.659-691

Texto religioso hindu, do épico Mahabharata, a Bhagavad Gita, ou apenas "Gita", é considerada uma das principais escrituras sagradas da Índia. Esta obra retrata o diálogo de Khrishna (uma das encarnações de Vishnu) com Arjuna (seu discípulo guerreiro) em pleno campo de batalha, no qual são colocados importantes pontos da filosofia indiana, principalmente o conhecimento da natureza do "Eu" e sua relação eterna com toda a criação e aquilo que a transcende.

Esclareço que, toda vez que estiver citando os aprendizados que obtive no curso da Gita, como ensinados na associação cultural Vidya Mandir, ${ }^{4}$ em Copacabana (RJ), me refiro ao diálogo permanente entre Krishna e Arjuna, já que é por meio desses "personagens" que todo o ensinamento é transmitido. Ressalto que este artigo está baseado nas aulas que assisti do curso da Gita, ${ }^{5}$ entre outros cursos de Vedanta, retratados em meu diário de campo entre 2009 e 2019. ${ }^{6}$ Trata-se, portanto, do meu entendimento a respeito da visão dos professores e alunos do Vidya Mandir sobre a tradição filosófica Vedanta, o estilo de vida de yoga e a busca soteriológica pela "liberação".

A Bhagavad Gita, que literalmente significa canção do Senhor, é um texto composto de dezoito capítulos, que está inserido no épico Mahabharata. Seus versos são escritos de forma poética, que é tradicionalmente cantada; é considerada sagrada pela maioria dos hindus e seus ensinamentos são narrados na forma de diálogo entre os primos Krishna (referido também como Bhagavan ou divino) e Arjuna, um

${ }^{4} \mathrm{O}$ local onde o grupo pesquisado se reúne é chamado Vidya Mandir, cujo significado é "templo do conhecimento", que é uma associação cultural sem fins lucrativos, localizada no bairro de Copacabana, Rio de Janeiro.

${ }^{5}$ Continuei frequentando outros cursos de Vedanta, após o término do curso da Bhagavad Gita, como o Tattvabodha, o Upadesasaram, o Atmabodhah, a Katha Upanishad, Mundaka Upanishad e a Taittiriya Upanishad.

${ }^{6}$ Apesar de meu primeiro contato com o grupo ter ocorrido em outubro de 2009 e, desde então, ter começado a pesquisar sobre essa tradição e entrevistado alguns de seus membros, comecei a frequentar o espaço do Vidya Mandir, de fato, apenas a partir de 2011. 
Religare, ISSN: 19826605, v.16, n.2, dezembro de 2019, p.659-691

príncipe guerreiro. Esse diálogo se passa no campo de batalha de Kurukshetra, antes do início da guerra contra os primos de Krishna e Arjuna.

Krishna, ao aconselhar Arjuna a respeito de sua confusão e dilema moral sobre ir à guerra contra seus perversos primos, explica ao primo a respeito de suas obrigações enquanto guerreiro e príncipe, quer dizer, seu papel naquela situação (seu dharma). Ele diz a Arjuna que, por mais detestável que seja, é seu dever lutar e vencer o exército de seus primos para assegurar o triunfo da verdade, da liberdade e bem-estar de seu povo. E o mais importante: Krishna ensina os fundamentos filosóficos para a vida cotidiana, dando exemplos e analogias - o que acaba se tornando não apenas um guia para a filosofia hindu, mas para a vida. Ao conciliar diversas perspectivas e linhas filosóficas, podemos dizer que a Gita tem uma influência que se estende muito além da Índia e da religião hindu. ${ }^{7}$

O diálogo entre Krishna e Arjuna, que compõe a Bhagavad Gita, tem, para os vedantinos, valor equivalente ao das Upanishads, cujos textos, em geral, explicam sobre o significado do Absoluto, quer dizer, aquilo que é além de qualquer "uma" visão de deus e, portanto, explicam o que pode ser entendido como uma realidade que é livre de formas. Sendo assim, não é o objetivo da Gita nem do Vedanta ensinar sobre uma religião ou uma visão de deus, mas sobre o que poderíamos chamar de realidade "maior" ou "fundamental".

Para Heinrich Zimmer (1979, p. 313), a Gita consiste em uma reunião e coordenação de todas as disciplinas fundamentais da complexa tradição religiosa da Índia e, além disso, introduz "um ponto de vista mais moderno, mais espiritual e mais psicológico". Ela discorre, diz o autor, sobre o entendimento da ação, quer dizer, de que a pessoa deve agir, porque na realidade ela agirá qualquer atividade

\footnotetext{
${ }^{7}$ Existe a tendência em se "traduzir" ou "sintetizar" o ensinamento filosófico ou "religioso" indiano, o que contribui para a disseminação desse ensinamento pelo mundo. Essa tendência já se encontrava presente na cultura da Índia desde a época do Mahabharata. Segundo Eliade (1996, p. 131), Krishna, na Bhagavad Gita, esforça-se "por reunir todos os caminhos soteriológicos em uma única e nova síntese espiritual".
} 
Religare, ISSN: 19826605, v.16, n.2, dezembro de 2019, p.659-691

que adote mas - essa seria a diferença -, ao agir, a pessoa deve conseguir se desapegar dos frutos da ação, o que faz com que a preocupação de seu ego se dissolva e, desse modo, a pessoa descobrirá o "Eu" - um "Eu" que não se preocupa com a individualidade interior, nem com o mundo exterior. Da perspectiva dos alunos de Vedanta, essa visão da Gita sobre o desapego ao fruto da ação seria um pouco simplista, pois o que acreditam não é em uma renúncia ao fruto da ação, mas na aquisição de uma capacidade de renunciar à reação ao receber o fruto da ação.

Krishna recomenda a Arjuna apresentar à mente o objetivo e a recompensa de práticas como a meditação, por exemplo, de forma que ela se preste às mudanças que estão sendo propostas, porque se o sujeito for muito rigoroso em suas práticas sem sentir prazer em realizá-las, será mais difícil e, assim que ele "relaxar" em seu rigor, a mente buscará o oposto, já que teria pouca tolerância à base da força.

A maneira de se comandar a mente seria dar uma "direção" a ela, da mesma forma que se segura as rédeas do cavalo, segurando e soltando-as. A imagem que normalmente vem acompanhada deste exemplo é a de Krishna segurando as cinco rédeas de sua charrete, cujo significado é entendido como estar "conduzindo" os sentidos. O que está sendo proposto é a construção de um novo hábito através da repetição da disciplina: a pessoa necessitará adquirir um novo hábito, já que a vida é construída com base em um estilo de vida, ao qual está habituada, e é nesse sentido que ela deverá conduzir sua mente repetidamente de forma a criar o novo hábito. A proposta dessas práticas se baseia no sentido de "comando" e não de "controle"; para os vedantinos, o controle estaria baseado no rigor e o comando no entendimento, e é desta forma que a pessoa conseguiria "conquistar" sua mente, realizando mudanças a partir de um entendimento.

\section{Karma yoga - adquirindo um "comando" sobre a mente}


Religare, ISSN: 19826605, v.16, n.2, dezembro de 2019, p.659-691

O principal método difundido na Gita é a aquisição de um "comando" sobre a mente através do karma yoga, sintetizado como "ter discernimento em cada ação realizada". Dentro do que é ensinado como yoga, Krishna mostra uma "fórmula" para adquirir maior objetividade emocional. O yoga trata basicamente da estrutura emocional da pessoa (suas reações e apegos às reações, aos desejos e a uma maneira de ser) e tem como proposta a aquisição de uma mente "objetiva" e "crítica" (de si). Ao observar certas reações e/ou emoções, é dito que os alunos conseguem se desapegar destas, ao invés de se identificar e pensar "eu sou assim". O objetivo é possuir uma mente mais clara e menos reativa e, dessa perspectiva, Krishna propõe a vivência de um estilo de vida que conduz à disciplina da mente, ao questionamento, ao autoconhecimento e a uma atitude que seja "moderada", sem os extremos em relação aos vários aspectos da vida. ${ }^{8}$

De acordo com Dharm Bhawuk (2008), a Gita descreve o karma yogi como alguém que desistiu de todos os desejos que vêm a sua mente e permanece satisfeito em seu self verdadeiro ou atma. ${ }^{9}$ Nesse estado, ele estaria livre de emoções como apego, medo e raiva e não ficaria agitado ao se deparar com a miséria, nem buscaria a felicidade; ele não teria afeição por ninguém, e também não se sentiria encantado quando coisas boas acontecem, ou se sentiria mal quando coisas más acontecem; ou

\footnotetext{
8 Segundo Carol Ryff (1989, p. 1078), a pessoa que tem metas e propósitos na vida se sente melhor psicologicamente. Essa "direção" em sua vida é "critério central de bem-estar psicológico", apesar de requerer dela esforço e disciplina.

${ }_{9}$ Dharm Bhawuk (2008, p. 394-395) também informa que o "Eu" metafísico, ou o atma, é definido como o "Eu" real ou verdadeiro na Gita, e suas características são apresentadas da seguinte maneira (interpretação do autor): o atma é aquele que não é suscetível à destruição, algo que não passa por modificação, é inexplicável, não conhecível e é eterno; o atma não mata ou é morto, nunca nasce ou morre, e transcende o tempo; o atma é não nascido, permanente e antigo, e não morre com o corpo. Deve ser entendido como o que tudo permeia, estável, imóvel, não manifesto, não modificável e além da percepção. É descrito como sendo simplesmente incrível de se ver, de se falar, e de se escutar, tão incrível que muitos de nós não o compreendemos. O autor propõe que a essência do ser humano, o verdadeiro "Eu", atma, seria eterno, e que, em contraste, a forma do ser humano, seu corpo, sua mente, seu ego, ou seja, seu "eu" aparente, chamado jiva, seria temporal.
} 
Religare, ISSN: 19826605, v.16, n.2, dezembro de 2019, p.659-691

seja, seus órgãos dos sentidos ficariam em seu completo controle e, assim, ele seria capaz de remover seu "escudo".

Yoga é, para Weber (1958, p. 165), uma forma suprema e específica de "conquista intelectualizada do sagrado", pois os sentimentos direcionados através de altos níveis de concentração devem primeiramente ser vivenciados com a maior consciência possível e, para alcançá-los, os sentimentos de afeição (ao Absoluto), compaixão (pelas criaturas), bem-aventurança e, finalmente, indiferença (para com o mundo) são buscados no self "de maneira planejada e racional" através de exercícios de meditação. A racionalização do "êxtase apático" através da meditação e da contemplação, propõe Weber (1958, p. 171), como a técnica ióguica de auto concentração, uma vez realizada consistentemente, desperta capacidades especiais e insuperáveis para vários processos psíquicos do self, particularmente estados de sentimentos; é alcançado, em consequência, o hábito ao interesse nos eventos e processos da vida psíquica, ao mesmo tempo em que o self se transforma em um observador desinteressado.

Entendo que os vedantinos, apesar de se engajarem em suas obrigações, se exercitam (mentalmente) de forma a estarem aptos a ir além da cognição e emoção quando se disciplinam para adquirir a capacidade de renunciar à reação ao receber o fruto da ação, no sentido de receber o que o mundo trás sem reagir - o que quer dizer agir com base no discernimento e de forma consciente. Mas esclareço que este exercício mental é praticado na forma de um ideal a ser conquistado e não já totalmente alcançado.

Como ensinado aos alunos de Vedanta, a Gita recomenda o método do karma yoga como superior a outros métodos de autorrealização, principalmente porque é uma orientação de Krishna para Arjuna, um guerreiro que estava inclinado a abandonar seu dharma a fim de não enfrentar a batalha, achando que a solução seria abandonar tudo e se isolar em algum lugar com a finalidade de se dedicar 
Religare, ISSN: 19826605, v.16, n.2, dezembro de 2019, p.659-691

unicamente ao conhecimento. Porém, se fosse uma orientação a outra pessoa, Krishna poderia ter recomendado o sannyasa, o caminho da renúncia, e não o karma yoga. Mas é exatamente por ser dessa maneira que a Gita parece atual, pois ela não sugere um abandono da sociedade, mas uma vida de conhecimento em meio à sociedade, como sugere Dumont (1985).

Entende-se que se a pessoa está em dúvida, como Arjuna estava, o melhor caminho a seguir é o karma yoga, pois ter dúvida significa que ela não estaria pronta para a segunda opção, sannyasa (da renúncia). Em contraposição, para aqueles que têm a inclinação para a renúncia, isto é, que não estão em dúvida sobre qual caminho seguir, pois a renúncia já está "neles", o melhor caminho/estilo de vida seria o sannyasa. Acima de tudo, mesmo quando a pessoa escolhe karma yoga à sannyasa, ela também precisa estudar e ter uma vida de renúncias e conhecimento, pois o estudo - a busca pelo conhecimento do "Eu" - não é opcional, mas fundamental nos dois caminhos/estilos de vida. ${ }^{10}$

Duas questões salientadas por Arjuna que julgo importantes descrever: quando a pessoa se torna "integrada"?; e quando se pode dizer que a pessoa está conduzindo sua vida com equilíbrio? A resposta de Krishna é: “quando a pessoa se torna moderada", no sentido de equilibrada, sem favorecer os extremos e fazendo escolhas com sabedoria e discernimento. Não haveria uma fórmula ou receita, pois depende de cada situação; como a vida não é "padronizada" e não se sabe o que virá a seguir, não é possível controlar as situações, pois há sempre um novo fator que surge e surpreende, e não se sabe de onde surgiu. Krishna enfatiza não ser uma questão de obedecer a uma regra ou ter uma mente obediente, que aja de determinada

\footnotetext{
${ }^{10}$ Inúmeras vezes, na Gita, Arjuna levanta a questão de se a pessoa se dedicar somente ao estudo não seria melhor do que permanecer na sociedade, quer dizer, ele tem a noção idealizada de que, para a pessoa adquirir conhecimento e alcançar a liberação, é necessário se tornar um renunciante, no sentido de se isolar da sociedade. E Krishna responde que a pessoa que renuncia a tudo e se dedica totalmente ao estudo deve estar preparada para tal empreendimento, pois se não estiver, ela irá se desgastar usando toda a energia em algo que não a levará a liberação.
} 
Religare, ISSN: 19826605, v.16, n.2, dezembro de 2019, p.659-691

maneira, preestabelecida, mas de praticar uma disciplina, no sentido de poder ser o mais equilibrado e sábio possível nas situações que se apresentam, ou seja, ter sabedoria para escolher o melhor ou mais sensato possível.

Como as situações são inesperadas, Krishna defende a necessidade de ter um preparo, manter o equilíbrio e a paz internamente, a fim de que a sabedoria e o discernimento possam estar disponíveis na hora em que são necessários. Com uma mente disciplinada, Krishna propõe, a pessoa permanece em si mesmo, no atma. Em "si" significa "independente" dos objetos para ser feliz, com capacidade de estar confortável consigo e com a mente "focada". Dessa forma, a mente descobriria não apenas shanti, o momento de paz, mas "eu sou a paz" - apesar dos pensamentos. Isso implica não haver necessidade de "eliminar" os pensamentos, mas descobrir satisfação e suficiência em si mesmo. Quando isso acontece, essa pessoa é chamada de yogi.

Krishna define duas noções de felicidade. Uma seria a felicidade que tem fim, que é aquela que tem uma causa em alguma coisa, "por causa disso" a pessoa está feliz: ou porque alguém apareceu, ou porque as coisas aconteceram como a pessoa desejou, ou porque a pessoa recebeu uma boa notícia, enfim, tem um começo e um fim. A outra seria a felicidade sem fim, que é definida como não sendo uma euforia, um estado produzido por ter alcançado algo, mas um estado de paz, tranquilidade e conforto em si, independente de situações e livre de desejos. Esse sentimento é entendido como não havendo absolutamente nada que a pessoa queira para ser feliz, porque ela já está bem consigo mesma; ou seja, a felicidade não estaria mais relacionada à percepção do objeto ou à experiência do objeto, nem a algum acontecimento, mas com aquilo que estaria "além dos sentidos". É, portanto, entendida como "a paz que eu sou", no sentido de as situações estarem "bem do jeito que estão" e "o coração estar cheio". 
Religare, ISSN: 19826605, v.16, n.2, dezembro de 2019, p.659-691

De acordo com este ensinamento, compreende-se que o mundo pode não ter mudado, as situações podem não ter sido resolvidas, tudo pode estar igual ao que era antes e a única coisa que se transforma é uma certa visão de mundo ou maneira de se pensar: uma percepção e entendimento da suficiência em si mesmo. Sendo assim, não faz sentido esperar o dia em que o mundo estará bem, porque nunca estará, mas o coração da pessoa estará satisfeito e pleno, porque haveria a percepção dessa presença do "Eu" que é completo e é a paz.

Seguindo essa linha de raciocínio, quando se questiona a felicidade e se pergunta, "onde está o momento de felicidade?", a pessoa se dá conta de que teve uma experiência de felicidade que, normalmente, está associada a uma situação, a uma pessoa ou a um objeto - foi causada por algo. Aquela pessoa ou objeto pode ter sido um instrumento que causou o relaxamento da mente, mas a questão que surge seria: é ali que está localizada a felicidade? A resposta é não, pois Krishna indica, na Gita, que a felicidade está localizada dentro de si; ela deve ser entendida como "eu sou feliz" e não ligada a acontecimentos externos. A felicidade seria o sujeito e não a mente ou um pensamento (porque o pensamento seria eu $e$ o pensamento de felicidade e não $a$ felicidade); desse modo, ela seria o próprio sujeito, que é entendido como completo e "livre" de desejos.

Na Gita, aprendemos que o sábio é aquele que, mesmo que por um determinado momento qualquer pensamento possa se impor, rapidamente ele retorna a visão clara de si, voltando a sentir a paz como sendo "eu sou a paz"; e o "ignorante" (em relação ao conhecimento do Eu) é aquele que não tem essa visão do sujeito e que, em cada pensamento, "vai" junto com o pensamento: pensamento de alegria, ele fica "tão" alegre hoje, pensamento de tristeza, fica "tão" triste hoje. O sábio, em contraste, seria aquele cujo pensamento não se impõe, já que ele estaria "além" do pensamento. 
Religare, ISSN: 19826605, v.16, n.2, dezembro de 2019, p.659-691

Chamo atenção para o caráter bastante racional do ethos vedantino. Essa racionalidade, segundo Weber (1958, p. 170), seria apenas um instrumento para alcançar o objetivo da meditação ou contemplação, estas não necessariamente se tornam um abandono passivo aos sonhos ou a simples auto-hipnose (embora possam chegar a tais estados na prática); ao contrário, o caminho específico para a contemplação seria uma concentração bastante energética em certas verdades, que chegam a assumir uma posição central internamente e a exercer uma influência integradora sobre a visão total do mundo. Por outro lado, o yogi, chamado por Weber de "místico contemplativo" não percebe o significado essencial do mundo e daí o compreende de forma racional, pela mesma razão que ele já concebeu o significado essencial do mundo como uma unidade além de toda realidade empírica. É dessa maneira que a contemplação nem sempre resultou em um abandono do mundo social no sentido de evitar qualquer contato com este mas, ao contrário, esse indivíduo pode requerer de si a manutenção de seu estado pleno contra cada pressão da ordem mundana, como um índice do caráter permanente deste estado.

Da perspectiva desse caráter racional contemplativo, a "ausência de apego" é entendida como o estado de mente no qual a pessoa aceita qualquer acontecimento ou coisa que venha em seu caminho como ele/ela é, sem se encantar demais com a felicidade ou se lamentar demais na infelicidade, mantendo assim um equilíbrio na prosperidade e adversidade. Mesmo que, por um momento, a pessoa tenha alcançado a plenitude e a satisfação, isso não quer dizer que sua vida ficará "perfeita"; acontecerão situações de grande perda ou sofrimento que não são esperadas nem desejadas pela pessoa. Mas, ainda assim, o sábio, em nenhuma situação, se distanciaria da visão do "Eu" que é completo e pleno; essa visão seria tão clara para ele que nada nem ninguém conseguiria perturbá-la.

Bhawuk (2008) explica que raga (emoção positiva) é gerada pela felicidade e dvesha (emoção negativa e hostil) é gerada pela infelicidade e que, quando os desejos 
Religare, ISSN: 19826605, v.16, n.2, dezembro de 2019, p.659-691

são realizados, a pessoa fica feliz e tem emoções positivas, o que logo a pressiona a buscar mais esses desejos. Por outro lado, quando os desejos não são realizados, ela fica triste e hostil aos eventos ou pessoas que são uma "barreira" no caminho de realização dos desejos. Dessa perspectiva, em um caso extremo, o pensamento de desejos não realizados pode gerar frustração, raiva e hostilidade, que geralmente é o caso com questões não resolvidas durante a infância, que impedem muitas pessoas de funcionarem "efetivamente" quando adultos. O autor defende que, quando realizamos a verdadeira natureza de nosso self, ou atma, há uma rejeição em relação aos elementos do mundo material. Essa abordagem através da realização, ou do não apego aos desejos, segundo Bhawuk, impede um desejo até de nascer, o que evitaria o sofrimento consequente; sendo assim, a compreensão de seus próprios desejos e o gerenciamento destes é algo fundamental na prática do yoga.

Arjuna pergunta à Krishna qual o significado de yoga. E Krishna responde poeticamente, em um jogo de palavras, que é "a separação da união com a dor"; a poesia se perde na tradução, pois yoga, literalmente, é união. Desse modo, a união com a dor ou sofrimento acontece através das experiências e pensamentos. Por exemplo, quando falamos "isso eu não gosto" ou "isso eu gosto e acabou tão rápido", há emoções de sofrimento, perda ou ansiedade que não estão de acordo com "meu" desejo ou "minha" expectativa. Devido à identificação com o corpo, tudo o que acontece com ele e com a mente estaria associado ao "eu" - o que seria um engano. E quando acontece uma situação desagradável, imediatamente a pessoa fica restrita àquela situação, vendo-se como "eu sou infeliz". ${ }^{11}$

No entanto, quando o indivíduo consegue discernir que é somente esta situação que não está resolvida, mas em outras áreas de sua vida está tudo bem, então conseguiria resolver o problema, que estaria localizado. E assim que o

\footnotetext{
${ }^{11}$ O problema seria porque a pessoa diz "eu sou infeliz", mas não "a situação é infeliz". Se a situação é difícil e a pessoa assume a "identidade do sofrimento", ela "inteira" se identifica com o sofrimento e, desse modo, fica difícil resolver o problema.
} 
Religare, ISSN: 19826605, v.16, n.2, dezembro de 2019, p.659-691

indivíduo localiza o problema e sabe que ele não é o problema, se tornaria o yogi alguém que se dissocia da identificação com a dor. Desse modo, ele lida com o problema, tenta resolvê-lo e, se não tem solução, não é um problema, mas um novo fato a ser aceito em sua vida. A partir desse momento, ele tem que "digerir" o fato. Essa atitude de yoga deve ser vivida e praticada a todo o momento, numa tentativa de se concentrar e perceber exatamente onde está localizado o sofrimento.

Outro questionamento trazido por Arjuna, na Gita, é sobre quem é o "Eu" e entende-se que, em todos os pensamentos, ele seja o silêncio e a paz. Deve-se estar atento a fim de perceber o silêncio entre os pensamentos; e ser capaz de ter uma mente que tem capacidade de estar bem consigo. Essa seria a mente do yogi. Com essa finalidade, há uma ênfase em um estilo de vida meditativo, que teria o significado de perceber a paz ao vivenciar as situações. $O$ objetivo seria trazer à mente a visão de quem é o "Eu". Em um sentido mais prático, Krishna ensina a Arjuna o método da meditação, ao explicar a finalidade de "disciplinar" a mente e, com isso, dá exemplos sobre meditar em um espaço "agradável" ou sobre a concentração da mente em mantras, entre outros.

É enfatizado a aquisição de paz e equilíbrio ao praticar a meditação, mas há necessidade de tratar a mente com "cuidado e carinho", para, dessa maneira, tornála "amiga", pois quando a mente é amiga de si, ela poderá ser "usada". Esse ensinamento está baseado no fato de ser possível conquistar a mente, ou conquistar a si mesmo, possuindo o comando sobre ela. ${ }^{12}$

\footnotetext{
${ }^{12}$ Em toda a Gita, Krishna não acredita em controle, é sempre um comando sobre a mente, uma visão das situações à medida que elas vêm. A mente é chamada de karana, quer dizer, instrumento. Tanto nossos sentidos quanto o instrumento interno, a mente, têm que ser usados por alguém; o instrumento não pode agir por si, ele deve ser preparado para o "nosso" uso, não devendo decidir por si próprio.
} 
Religare, ISSN: 19826605, v.16, n.2, dezembro de 2019, p.659-691

Ao aprender sobre o sentido de karma yoga ensinado na Gita, entendi o motivo da popularidade ${ }^{13}$ desse ensinamento - sua praticidade e racionalidade. Tudo o que os alunos ouvem é compreensível e racional. ${ }^{14}$ Existe a recomendação de que o maior desejo que alguém deve ter é a "liberdade da mente", que significa ter uma mente livre para pensar, para escolher, o que acontece quando não se está preso a um padrão de reação e comportamento, pois estando no mesmo padrão, de raiva ou fingimento, a mente continuaria se comportando dessa maneira, indefinidamente. A partir disso, ficar livre da raiva, da cobiça e dos desejos não seria visto como não ter raiva, cobiça ou desejo, pois é natural ter esses sentimentos. Estar "livre" é reconhecer quando uma raiva ou desejo "cego" estão tomando forma e afastá-los de sua mente, não se deixando "dominar" por eles.

Existiria uma diferença em relação aos impulsos: para o sábio, eles têm certas características, porque ele percebe quando alguns sinais (físicos e mentais) começam a se manifestar; e o "iludido" (em relação ao Eu) é aquele que só percebe quando os impulsos já estão manifestos. Apesar de, em ambos os casos, ser o mesmo impulso, a diferença é que o sábio perceberia quando o impulso não está manifesto ainda: ele teria consciência dos impulsos tal como uma onda quando começa a se formar; não se visualiza nem seu topo ou crista ainda. $\mathrm{O}$ "iludido", por outro lado, seria aquele que só percebe quando o impulso já está manifesto: quando a onda já teria acabado de estourar.

\footnotetext{
${ }^{13}$ Como Heelas (2008) supõe, as técnicas orientais estão se propagando em todo o mundo e é possível entender aulas de yoga e/ou meditação como um mercado que não para de crescer entre as ofertas de produtos Nova Era.

14 Vejo um paralelo do que está sendo proposto como karma yoga com a visão aristotélica de eudaimonia, que considera o bem-estar não como um estado de prazer versus sofrimento, mas de viver bem, que envolveria a aspiração ativa e explícita pelo que seja válido e de dignidade humana inerente e intrínseca, também sendo caracterizada pela reflexividade e razão, de busca voluntária, sendo expressão do self ao invés de produto de controle ou ignorância externo - em suma, envolveria o estar ativa e reflexivamente engajado na tomada de decisões e agir segundo meios que representam a realização da mais elevada natureza humana (RYAN, HUTA \& DECI, 2008).
} 
Religare, ISSN: 19826605, v.16, n.2, dezembro de 2019, p.659-691

Tudo aquilo de que uma pessoa depende para viver é entendido como uma forma de limitação, porque ela não consegue ser feliz sem aquilo e, entretanto, "abrir mão" teria o significado de estar livre daquilo. O desapego total, portanto, significa que em qualquer situação que o mundo traga para a pessoa, ela estará bem. ${ }^{15}$ É enfatizado que não é "não fazendo nada" que a pessoa estará livre da ação, já que aquele que faz a ação está "amarrado" a ela. Ainda que a pessoa esteja parada, existe uma ação: a ação da decisão de não fazer nada, o que já seria uma escolha. A mente (junto com o corpo) sempre fará escolhas que serão boas ou ruins, o que quer dizer que a pessoa estará "amarrada" ao resultado e, com isso, entende-se que estar livre da ação não é algo possível para aquele que possui um corpo. Então como é possível estar livre da ação? A questão é descobrir quem, por natureza, é livre da ação. É nesse sentido que seria um engano achar que através da "renúncia da ação" a pessoa está livre, pois quem é livre da ação é aquele que, por natureza, já é livre - a consciência, que é presença, que não possui instrumento de ação (nem mental nem física).

\section{Distanciamento de si}

É ensinado que a pessoa deve ter clareza de mente até mesmo quando erra, fica com raiva e diz: "fiquei com muita raiva". Só o fato de reconhecer que ficou com raiva já pode ser considerado como tendo "clareza". Por outro lado, se ela se identifica com a raiva, não consegue dizer que ficou com raiva, já que continua com o sentimento: ela "carregaria" a raiva em sua identificação. O sábio ou yogi é entendido, na Gita, como sendo livre de impulsos, já que possui um comando sobre

\footnotetext{
${ }^{15}$ A questão central que Dumont (1970) enfatiza é que, graças ao amor, a renúncia foi "transcendida" por ser "internalizada", quer dizer, para que seja possível escapar o determinismo das ações, a inatividade não é mais necessária, sendo o desapego e o desinteresse suficientes, já que a pessoa pode "deixar o mundo" internamente.
} 
Religare, ISSN: 19826605, v.16, n.2, dezembro de 2019, p.659-691

eles; ele conhece muito bem sua mente e tem um comando sobre ela, porque os impulsos não "ganham espaço" ali.

Entendo que o ideal ióguico seja viver como alguém que percebe e entende certa lógica dos impulsos e consegue não reagir às situações que são desencadeadas por eles. Disciplinar ou comandar a mente, dessa perspectiva, está diretamente ligado ao conhecimento de suas ações e reações, pois quando o yogi entende como sua mente funciona e percebe as reações a diferentes estímulos e sentimentos, ele teria um comando sobre eles - ao ver a si mesmo "de fora" de si mesmo, é possível não deixar as reações "assumirem o controle" e, com isso, ter mais racionalidade quanto aos sentimentos. Quando alguém reage, por exemplo, tendo um "ataque" de raiva ou de ciúmes, ele se "deixa levar" pelos impulsos e, desse modo, agiria "sem discernimento".

O sofrimento, como ensinado, é desencadeado através das reações da mente e da ilusão que mantêm a pessoa na ignorância. Liberação, para os vedantinos, não é "trazer" consciência (ou trazer alguma coisa), mas apenas reconhecer aquilo que a pessoa já é, nesse momento que existe ignorância. A pessoa já seria aquilo que quer ser (liberada), mas a ignorância a incapacita de entender isso, desse modo ela continua uma buscadora (ela continua buscando o autoconhecimento) - não pela falta daquilo que é, mas porque não consegue perceber o que é. Portanto, existe sofrimento, que é entendido como consequência da ilusão do que a pessoa, na realidade, é.

De acordo com Neil Dalal (2005), não há estruturas definidas ou parâmetros que limitam o autoconhecimento, pois este não seria uma criação, mas a remoção da ignorância, que estaria "cobrindo" a verdadeira natureza do atma e projetando a sobreposição do ego na mente e corpo. Ou seja, não há expectativas de conhecimento que criam uma experiência (exceto para o mal informado), pois o autoconhecimento não é concebido fora de si mesmo e não há descrições fenomenológicas do 
Religare, ISSN: 19826605, v.16, n.2, dezembro de 2019, p.659-691

conhecimento em si, o que significa que o autoconhecimento não é algo que poderia ser criado - ele já existe e o aluno precisaria apenas reconhecê-lo (ao se "livrar" da ignorância).

Um dos principais ensinamentos da Gita diz respeito ao que entendo como distanciamento de si, que significa ver a situação como ela é ("ver" o que a mente está pensando) como se fosse alguém "de fora" (tendo um distanciamento de si), conseguindo se enxergar como alguém que é "além" do corpo e mente. Como Zimmer (1979) explica, o indivíduo que adquiriu o conhecimento do Vedanta se comporta como uma pessoa que assiste a um espetáculo mágico - no qual o menestrel, por vários meios, cria a ilusão de um incêndio ou de uma inundação, ou de animais selvagens que estão prestes a atacar o auditório - sabendo que tudo é uma ilusão dos sentidos, uma obra de arte de magia. Embora veja algo, não considera que tenha realidade absoluta.

Faço uma analogia quanto ao que Nery (2003, p. 17) sugere como deslocamento: o indivíduo se colocaria "como espectador distanciado em relação ao próprio sentimento que o envolve naquela circunstância". Entender o Eu como além do corpo e mente, já que ele é atma para os vedantinos, envolve um deslocamento no sentido de entender a si mesmo como alguém que é além da pessoa que está pensando, falando e agindo, o que seria o primeiro passo para adquirir um comando sobre as emoções. O ideal ióguico busca, como ressaltado, o comando dos sentidos e emoções com a finalidade de autoconhecimento: de conhecer suas reações às emoções tendo, então, um comando maior sobre elas e sobre si.

De acordo com Heinrich Zimmer (1979, p. 127), na sociedade indiana, ninguém deve dar rédeas soltas aos impulsos, já que, desde o primeiro momento de vida, as energias individuais são "dominadas, encarrilhadas e coordenadas" pela sociedade. O comando dos sentidos, segundo Dasgupta (2009), ao produzir uma estabilidade dos desejos e pensamentos, deixa a mente fixa, em paz e imersa em 
Religare, ISSN: 19826605, v.16, n.2, dezembro de 2019, p.659-691

contentamento e satisfação, não no sentido de alcançar um estado de emancipação do self ou o fim absoluto de todos os processos mentais, mas alcançar a "constância" da mente, satisfação e o poder de entrar em contato com o Absoluto. Para o autor, o objetivo do autocontrole é uma maneira de integrar os sentidos à mente, porque é somente através deste meio que se adquire uma mente satisfeita e em paz, e um coração "limpo e tranquilo".

O comando dos sentidos não deve ser entendido como o mero comando externo das atividades e propensões a paixões e apetites, mas, explica Dasgupta (2009), no sentido de um controle interno da mente por detrás dos sentidos, ou seja, a pessoa deve não só deixar de cometer ações decorrentes de avareza ou desejo por reconhecimento, mas sua mente deve estar absolutamente "pura", totalmente "limpa" de todas as "impurezas" dos desejos dos sentidos. Ele afirma que a aquisição de poder para orientar a mente em certa direção forma a base de toda a superestrutura do código de conduta ético e virtuoso da Gita.

O comando da mente, como ensinado no curso, faz com que o indivíduo não se deixe levar pelas emoções, ou seja, quando a mente se torna equilibrada, com a capacidade de não ficar reagindo em extremos - em relação ao frio e calor, coisas desagradáveis e agradáveis, quando é elogiada e criticada. Ele busca possuir uma mente conquistada que consegue se "estabelecer no conhecimento" e com a capacidade de ficar em equilíbrio, já que são basicamente as reações que a fazem perdê-lo, circunstâncias que geralmente a levam "para cima" e "para baixo". Percebo que não se trata de uma mente paralisada, que se ausenta das situações ou que não sente ou percebe as coisas, mas de uma mente que, estando nas situações agradáveis ou não - teria capacidade de se organizar frente a adversidades e conseguiria não reagir.

A questão que busquei analisar, então, foi por que é interessante não reagir. Foi-me dito que, não reagindo, a pessoa encontra a paz. O ensinamento revela que a 
Religare, ISSN: 19826605, v.16, n.2, dezembro de 2019, p.659-691

felicidade não depende de objetos, mas vem de dentro; ou seja, os prazeres vão acontecer, mas a pessoa teria que entender que eles não carregam só a felicidade, mas a infelicidade, porque eles têm um início e fim, o que significa que, se a pessoa realmente gosta daquele objeto (o objeto no seu sentido maior, que pode ser alguém), quando ele acaba (ou quando esse alguém não está mais por perto), a pessoa reage ficando infeliz. Por outro lado, se é algo de que ela não gosta, quando o acontecimento acaba é que ela está feliz. Dessa perspectiva, o prazer teria uma duração certa, já que terá que terminar em algum momento e, à medida que ele se transforma, é também causador de sofrimento.

Quando a pessoa possui autoconhecimento, sua felicidade seria entendida como não mais dependente dos objetos, pois a experiência de felicidade que é duradoura, que não depende dos objetos, é entendida como a paz da mente quando a pessoa descobre a paz independente das situações. Um dos métodos propostos para alcançar esse tipo de mente é a meditação.

\section{A capacidade de estar consigo mesmo}

A primeira coisa que se deve fazer na meditação, Krishna recomenda, é esquecer o corpo, para ele não "atrapalhar" a concentração da mente e, em seguida, concentrar a mente, permanecendo em um lugar onde o indivíduo possa ficar só, recluso. Krishna repete constantemente que a mente vai se desconcentrar e ele terá que concentrá-la novamente; tantas vezes ela se desconcentrar, ele terá que fazer esse exercício, que é a meditação, a fim de concentrá-la. Não adianta ficar desmotivado porque sua mente desconcentra; se sua mente não desconcentrasse, ele entraria no estado de samadhi (estado não dualista de consciência no qual a mente 
Religare, ISSN: 19826605, v.16, n.2, dezembro de 2019, p.659-691

permanece concentrada). Se sua mente desconcentra é porque ele está no estado de meditação. ${ }^{16}$

Pelo que entendi, não há necessidade de ir para o alto de uma montanha ou para dentro uma caverna; na verdade a pessoa precisa apenas estar só, sem perturbação nenhuma; por exemplo, em seu quarto, com os telefones desligados, sem nenhuma companhia ou atividade no local. Mas também sem desejos na mente, pensando que a única coisa que deseja naquele momento, verdadeiramente, é meditar, estando só e aproveitando o momento, livre de qualquer outro desejo. Para que isto aconteça, é necessário um "relaxamento interno", mesmo que seja por poucos minutos.

A meditação, dessa perspectiva, deve ser entendida como a "capacidade de estar consigo", já que se trata de um estado interno. Não seria apenas ficar sentado ou a postura que determina se a pessoa está meditando, pois isto não importa, contanto que o corpo fique relaxado e a coluna ereta; se ela não puder se sentar no chão e preferir a cadeira, não há problema, o essencial é não haver preocupação, estando, assim, livre de posse - ilustrado como não estar pensando em objetos, situações, "o seu projeto" ou "escritório".

É enfatizado que, na meditação, o corpo pode ser visto e a sensação que a pessoa tem é de não ser o corpo, já que ele é um instrumento a seu dispor, pois a pessoa seria mais que só o corpo e, assim, perceberia o "Eu" livre do corpo. É nesse sentido que a meditação proporciona um distanciamento em relação ao corpo. Ainda que ela entenda a equação "eu sou o atma", a identificação com o corpo é muito grande e a meditação auxiliaria a enxergar o corpo como objeto.

A preocupação com o corpo é considerada como a base criadora de todos os problemas, ou seja, existe uma sensação de ser o corpo, mesmo que o intelecto diga

\footnotetext{
${ }^{16}$ Logo, é enfatizado que, ao iniciar a prática, a mente irá desconcentrar muito e rapidamente, mas que, com a própria prática mais desenvolvida, ela irá desconcentrar menos, quer dizer, ele terá que "trazer a mente de volta" menos vezes.
} 
Religare, ISSN: 19826605, v.16, n.2, dezembro de 2019, p.659-691

não ser corpo nem mente. "Lá no fundo" existiria uma conclusão que não desaparece tão facilmente, o que faz com que a pessoa funcione a partir de uma preocupação em "como eu estou" querendo dizer "como está o corpo". Essa identificação seria um obstáculo que pode ser eliminado através da meditação. ${ }^{17}$

É entendido que o estudo em conjunto com a meditação elimina essa identificação e a substitui pelo atma ("Eu" consciência), mas sua identificação com o atma tem que permanecer firme para que a identificação corpo-mente permaneça em segundo plano. Apesar de ser através do estudo de Vedanta que a percepção do "Eu" consciência é compreendida, é na meditação que a pessoa tem a oportunidade de contemplar sobre o aprendizado e perceber o "Eu" que é completo. A meditação, dessa perspectiva, auxilia a assimilar o que se estudou, estabelecendo o atma e enfraquecendo a outra visão. Existe aí a aquisição de um conhecimento encorporado, 18 já que a proposta é estar "mergulhado" nesse ensinamento e, entendê-lo, seria transformador.

Krishna ensina que existem algumas tendências que aprisionam a mente e não se consegue ver além delas; são ideias que entram na mente e que, geralmente, não se raciocina sobre elas, como a crença, por exemplo, de que a pessoa só está bem "com os objetos", o que significa que seus momentos de felicidade estão associados à presença de objetos ou situações. Na medida em que ela, sozinha, descobre um momento de paz, ela obtém a capacidade de estar satisfeita sem nenhum objeto, porque existe alguma coisa nela que lhe transmite isto. Na meditação existe a percepção de que a paz não vem de fora, mas tem origem em si e, com isso, a

\footnotetext{
17 Por outro lado, a questão também não seria descuidar do corpo, não fazer exercícios ou se desapegar da comida, mas entender que a identificação com o corpo e mente é um engano. A pessoa teria obrigação de cuidar do corpo e mente, já que são entendidos como instrumentos, mas sem identificar-se somente com eles. Para isso, ela teria que descobrir outro significado do "Eu" a fim de não estar referenciado a estes.

${ }^{18}$ Encorporado aqui está traduzido do inglês, do sentido de embodiment. Entendo que a transmissão da tradição oral, como diz Schechner (2013), seja uma memória que fique encorporada.
} 
Religare, ISSN: 19826605, v.16, n.2, dezembro de 2019, p.659-691

percepção de que a própria pessoa seria a fonte de toda felicidade. Devido à descoberta de estar bem consigo, outra capacidade adquirida seria a possibilidade de estar bem com os outros. A questão não seria precisar estar com pessoas, mas ter prazer em estar com elas, não tendo nada a "ganhar" com isso a não ser o prazer daquele momento.

Durante a meditação, o indivíduo tende a objetificar o corpo ao vê-lo relaxado e, desse modo, entende que o corpo-mente está relaxado porque ele é a paz e o silêncio, quer dizer, ele enxergaria um "Eu" que é a paz, pois o "Eu" não estaria relaxado, já que seria a paz "por natureza". Existe, aí, uma distância sujeito-objeto; ao ver o corpo e mente relaxados e perceber que não é o corpo-mente, o indivíduo teria consciência de que é o silêncio e a paz, ou a "fonte de todo o prazer e felicidade". Na Gita, é dito que esta visão ocorre durante a meditação, mas se manifesta junto ao aprendizado.

\section{"Eu": a pura consciência}

Ao participar das aulas da Gita, tentei compreender como os alunos entendem o "Eu" consciência. Ele não é visto nem como o corpo nem como pensamento ou emoção, porque para dizer qual emoção a pessoa está sentindo, há necessidade de separar um outro Eu que diz "estou sentindo isso e aquilo". Seria necessário, então, separar os "Eus" e dizer, "eu estou consciente do sentimento que existe na minha mente neste momento em que falo com você" ; mas se as pessoas se comunicassem dessa forma seria confuso, por isso dizem apenas "eu sinto". No entanto, é ensinado que o pensamento e o sentimento são objetos, porque além de o indivíduo iluminá-los, ele é consciência que ilumina o pensamento, a percepção, as sensações e os sentimentos.

Desse modo, a consciência não faria nada, tudo aconteceria na presença dela; isto posto, ela mesma não tem "para onde ir", porque não tem um lugar onde não 
Religare, ISSN: 19826605, v.16, n.2, dezembro de 2019, p.659-691

esteja, já que ela é a base de todo o universo; e se a base de todo o universo é o espaço, isto significa que ela existe no espaço mas, como o espaço é "objeto" percebido e iluminado pela consciência, desse modo, ela é entendida como a base que sustenta tudo (universo e espaço). Apesar de ser uma única, quando a consciência ilumina o corpo do indivíduo, acredita-se que seja sua natureza; ela não seria o indivíduo, ela apenas é. Nesse caso, quando ela está iluminando a entidade indivíduo, é entendida como sua verdade essencial. Conclui-se então que o indivíduo está em todo o lugar, ou seja, não está somente nesse corpo, mas em todo o universo, já que a base de todo o universo é a consciência.

Entendo essa questão no sentido de a pessoa, no "plano comum", perceber o objeto. Ela é a consciência, sendo que a outra entidade nesse plano comum seria o objeto. Dessa perspectiva, o objeto é visto e a pessoa vê, só que, se ela é entendida como essencialmente consciência, o objeto também seria consciência, porque ele existe na consciência, mas ele não é consciente, porque para ser consciente é necessário um instrumento de reflexão, como o corpo sutil. Apesar de existirem várias qualidades que diferenciam, o que ilumina é uma mesma consciência, ou seja, a consciência não seria individual, mas o todo, uma única, que adquire qualidades diferenciadas através do corpo/mente, que é diferenciado. Assim, essa consciência é entendida como o espaço: ela está em todo lugar e tudo sustenta, mas aparece como refletida em cada corpo, tornando-se, portanto, esse "individual”, apesar de não ser. ${ }^{19}$

A consciência refletida em cada corpo/mente é entendida como uma "parte", da mesma maneira que, quando o sol se reflete num lago, esse reflexo é como se fosse uma parte do sol. Dessa perspectiva, quando a pessoa se identifica com o

\footnotetext{
${ }^{19}$ A luz do sol, por exemplo, além de iluminar, pode se refletir em um lago ou espelho e, então, ela se "reproduz", no sentido de "parecer" um sol. O mesmo acontece com a consciência, ou seja, em alguns elementos, que são sutis como a mente e os sentidos, além de iluminar, ela se refletiria, criando assim uma unidade: o indivíduo, ou jiva. A consciência seria uma no mesmo sentido que o sol é um. Por exemplo, se há cinco espelhos em direção ao sol, aparecem cinco sóis, mas o sol continua sendo um só - o mesmo com a consciência, ela estaria refletida nessas pessoas, mas é uma única.
} 
Religare, ISSN: 19826605, v.16, n.2, dezembro de 2019, p.659-691

corpo/mente, ela é um indivíduo, jiva, mas quando se identifica com a consciência, ela é "livre de limitação". A consciência, como se fosse uma parte do jiva, tornariase, assim, uma individualidade e se manifestaria nesse mundo dos indivíduos todos eles fundamentalmente consciência. Apesar de esse jiva, ao "tomar" para si essa reflexão da consciência, tornar-se como que uma individualidade nesse corpo/mente, fundamentalmente ele seria uma única consciência, ou seja, apesar de aparentemente separados e diferentes, somos fundamentalmente esse um, que é a consciência.

Segundo a tradição védica, o mundo, como é, não tem existência absoluta, sendo visto como passageiro até o momento em que o conhecimento verdadeiro é adquirido e a realidade absoluta é compreendida. Assim, tão logo se percebe que a única verdade é o atma ou "Eu" consciência, todas as percepções ilusórias que representam esse mundo como um "campo de experiências" cessam, assegura Dasgupta (2004), e isso não acontece porque as conexões do self com o mundo cessam, mas porque o processo de "mundo de aparências" não mais representa a "última" verdade sobre ele. Dessa perspectiva, não há dúvida de que essas experiências mostram uma ordem estabelecida, que tem suas próprias leis, mas isso não representaria a verdade última, pois elas são verdadeiras somente em um sentido relativo, enquanto parecem ser e, no momento em que a verdade última sobre elas e sobre o selfé compreendida, todo esse "mundo de aparências" se torna aparente, o que significa que a verdade única, consciência ou Brahman (pura existência e inteligência) ilumina na forma da ordem cósmica e suas leis.

O "mundo de aparências" enquanto vivenciado por nós, explica Dasgupta (2004, p. 441), está frequentemente relacionado à percepção ilusória do brilho da prata na madrepérola (no interior da concha): no momento em que a percepção parece verdadeira e a pessoa tenta pegá-la, como se a madrepérola no interior da concha fosse um objeto real confeccionado em prata, ela percebe que o objeto não é 
Religare, ISSN: 19826605, v.16, n.2, dezembro de 2019, p.659-691

real, é apenas uma madrepérola e, então, ela vira de costas e não é mais iludida ou atraída pela aparência. A ilusão da prata em si é inexplicável, pois era verdadeira para todos os propósitos enquanto persistia, mas quando o conhecimento verdadeiro foi adquirido, ela em seguida desapareceu. Dasgupta acredita que o mundo de aparências também desaparece quando o conhecimento verdadeiro da realidade se revela, pois quando o conhecimento falso é uma vez descoberto como falso, ele não retorna mais, já que uma ilusão não pode durar quando a verdade é conhecida.

Como ensinado no Vidya Mandir, a verdade última e absoluta é o "Eu”, que é um, embora parecendo ser muitos e diferentes. Em vista disso, o mundo, como separado de nós, indivíduos, não teria realidade absoluta, o que quer dizer que todos os eventos, mentais e físicos, devem ser entendidos como aparentes e em constante transformação, enquanto que a única verdade absoluta e imutável sob eles seria o "Eu". Para Dasgupta, ao menos que a mente seja "varrida" de todas as paixões e desejos, ela não poderá compreender essa verdade, mas uma vez que a mente esteja "livre" desses pensamentos e ansiosa pela liberação, um mestre instruirá o indivíduo com o seguinte ensinamento, "Tat Tvam Asi", que tem o significado de absoluta igualdade entre a realidade última, consciência ou Brahman, e o indivíduo, Jiva. Segundo o autor, o indivíduo, imediatamente ao entender essa instrução de seu mestre, torna-se a própria verdade, que é idêntica à pura felicidade e inteligência; logo, todas as noções e cognições da diversidade cessam, não havendo dualidade, noção do "meu" e "teu" e o indivíduo, por conseguinte, "brilharia" como a pura verdade.

Chamo a atenção para a seguinte analogia do "Eu" com um pote de barro. $\mathrm{O}$ pote é de barro e a pessoa consegue ver o barro isolado da forma. Da mesma maneira, a pessoa é a consciência que independe dos sentidos e da mente e, assim, possuir sentido e mente não a atrapalharia se ela sabe que é consciência. A pessoa 
Religare, ISSN: 19826605, v.16, n.2, dezembro de 2019, p.659-691

diz "não estou conseguindo enxergar o atma, porque os pensamentos me atrapalham; eu quero eliminar os pensamentos", o que teria o mesmo significado que dizer, "elimina esse pote porque está me atrapalhando de perceber o barro". É demonstrado, então, que os pensamentos não atrapalham, desde que a pessoa entenda que é, fundamentalmente, consciência, que assume várias formas e, assim, qualquer forma que assuma não causa nenhum problema quando ela sabe que é consciência. $^{20}$

Esclareço que o Vedanta não apenas ensina "eu sou atma"; é necessário o entendimento de várias questões que surgirão daí. Dúvidas fazem parte; a pessoa sente necessidade de questionar e saber como é o atma e, enquanto as dúvidas não forem eliminadas, o conhecimento não estará completo. Então o conhecimento ilumina o atma, mas ainda que a consciência seja da natureza de luz e ilumine sempre, vimos que sua existência não é suficiente, já que existe a necessidade de ser apontada.

A tradição védica diz que, ao adquirir esse conhecimento, a pessoa encontra a plenitude e satisfação em si mesmo. Ela é chamada yogi, alguém que possui conhecimento e clareza. A pessoa se divertiria da mesma maneira que uma criança quando se concentra em alguma coisa, o que significa que sua mente estaria completamente envolvida com aquela atividade e com a satisfação fornecida pela atividade. ${ }^{21}$ Este estado de mente seria equivalente a um estado de envolvimento

\footnotetext{
${ }^{20}$ A ignorância, dessa perspectiva, é entendida da seguinte maneira: como a mente não entende "eu sou o atma", ela pensa ser várias coisas, porque não existe conhecimento de quem o indivíduo realmente é. E por que não existe esse conhecimento? Porque ele nunca estudou sobre o atma e também porque existem várias identidades em relação ao " $E u^{\prime \prime}$ e, enquanto ele não obtiver conhecimento sobre esse "Eu", não haverá um pensamento na forma de "eu sou atma"; mas, uma vez estabelecido o conhecimento, a ignorância desaparecerá.

${ }^{21}$ Há semelhanças nesse que está sendo explicado na Gita e o estado de mente descrito por Kathryn Rountree (2006), que se refere à experiência dos peregrinos denominados "neo-pagãos". De acordo com a autora, no estado "fluído", os indivíduos - quer estejam escalando, jogando xadrez, navegando no oceano ou fazendo uma peregrinação - temporariamente perdem seu sentido de tempo normal, integrando ação e consciência, o que os leva a uma perda temporária do ego, experimentando assim um sentido de self realçado ou transcendente e uma aproximação intensa - a communitas de Victor
} 
Religare, ISSN: 19826605, v.16, n.2, dezembro de 2019, p.659-691

completo em alguma atividade; a pessoa não estará pensando, "o que eu vou fazer depois?", pois há um total prazer por estar ali. Este é um momento no qual todas as outras coisas são esquecidas, "deixadas de lado", o que não aconteceria deliberada ou naturalmente. É nesse sentido que o yogi, com a mente completamente envolvida na apreciação do atma, alcançaria a plenitude.

Para os vedantinos, uma pessoa satisfeita tem a sensação de "suficiência" não permanecendo com o sentimento de que "falta" algo e, ao mesmo tempo, ela é "firme" e "imutável"; ela deve ser entendida como "estabelecida" nesse conhecimento e com os sentidos sobre seu comando; assim ela é chamada de yogi (integrada). Uma questão que Arjuna indaga na Gita é em relação à atitude dessa pessoa frente ao mundo e ele entende que seria a de quem consegue se manter o mesmo frente aos objetos (por exemplo, frente a uma pedra, ao ouro ou à terra, cada um tem o seu papel, sua função, não tendo um valor maior, tendo apenas o valor por ele mesmo e nada além disso). A mesma coisa aconteceria frente a várias pessoas.

A virtude da igualdade (samatva) é o grande ideal que a Gita enfatiza, explica Dasgupta (2009), e ela pode ser adquirida em três estágios diferentes: o da igualdade subjetiva (o mesmo sentimento na alegria ou na tristeza, elogio e culpa, em todas as situações da vida); igualdade objetiva (considerando todas as pessoas, boas, más ou indiferentes, um amigo ou um inimigo, sob um olhar igual e com o mesmo espírito imparcial); e o estágio final para se alcançar essa igualdade é o de autorrealização (que é o estágio no qual a pessoa não é, de maneira alguma, perturbada por coisas mundanas - um estado de "transcendência”).

No curso que frequentei, essa atitude também foi enfatizada, mas com ressalvas: não são todos os tipos de pessoas que seriam "iguais"; a igualdade não se

Turner (1974) - às vezes eufórica, com outros, compartilhando seu estado de liminaridade. Para os peregrinos pagãos, como sugere, a incorporação ao ambiente sagrado pode ser experienciada como uma corrente de consciência entre pessoa e lugar, um encontro com o divino. 
Religare, ISSN: 19826605, v.16, n.2, dezembro de 2019, p.659-691

refere a uma atitude de olhar para todo mundo "igual", já que não são todos seus "amigos" e isto não seria uma atitude "objetiva" frente à vida. Há necessidade de saber exatamente como as pessoas são na hora que se agem, para agir da melhor maneira possível com os outros. É enfatizado, portanto, a pessoa ter uma atitude "objetiva" frente à vida e às pessoas, sem um valor subjetivo (a questão não é gostar ou não de alguém, mas saber como as pessoas agem). Dessa maneira, com “objetividade", ela conseguiria manter a mente constante.

De acordo com os Vedas, tudo o que existe no mundo material é composto pelos gunas: sattva, rajas e tamas, que são descritos por Dasgupta (2009) como a "característica universal de todas as tendências mentais". Dessa forma, o "guna sattva" é caracterizado por limpeza, lealdade, responsabilidade, disciplina, equilíbrio mental, controle dos sentidos, clareza de mente etc., enquanto que o "guna rajas" é sintetizado pela atividade intensa, desejo por gratificação, ganância, pouco interesse na ascensão espiritual, insatisfação, impureza, inveja e uma mentalidade materialista; e por fim, o "guna tamas" tem as seguintes características: raiva, ignorância, depressão, arrogância, preguiça, desequilíbrio mental, sentimento de impotência etc. Para Zimmer (1979), quem é igual frente à honra e à desonra, no calor e no frio, no prazer e na dor e é livre de todo apego tem a mente firme e se encontra cheio de auto-renúncia; ele tem uma atitude de indiferença aos gunas e não está "agitado" por estes. Ele simplesmente sabe que os gunas estão atuando por si mesmos, girando em redemoinho e, mesmo assim, ele permanece imóvel, sem desviar sua mente, estando além dos gunas.

Durante as aulas da Gita, um verso do capítulo doze da Gita é traduzido como "a pessoa que alcança a mim entendendo que eu estou em todo o lugar, permanecendo constantemente na identidade do Um - esse é o yogi. Qualquer que seja a forma de essa pessoa viver (seu estilo de vida), esse yogi está sempre comigo, em mim". É explicado que, quando há uma visão clara desse conhecimento, não há 
Religare, ISSN: 19826605, v.16, n.2, dezembro de 2019, p.659-691

necessidade de se esforçar, pois a visão estará sempre ali, qualquer que seja o estilo de vida da pessoa; quando esse conhecimento está estabelecido, ele será permanente e a visão será clara, já que o entendimento foi adquirido. É nesse sentido que os vedantinos entendem a necessidade de não viver de uma maneira predefinida, já que não há um comando a respeito da maneira como se deve viver, pois a pessoa se tornaria um "exemplo", não no sentido de como ela vive, mas do tipo de mente que tem.

Dessa perspectiva, portanto, "ver" as pessoas da mesma maneira teria o significado de ver a todos como não diferentes de si, quer dizer, vê-los com a mesma tolerância e compreensão que se deve ter consigo mesmo. O que fundamenta esse entendimento é a compreensão do outro, na qual é possível entender até quem não tem a visão de "sabedoria". A pessoa teria a capacidade de entender quem não vive uma vida coerente e de autoconhecimento ao se lembrar de como sua própria vida era antes, na qual não havia clareza, ou seja, ela deve ter a si mesmo no passado como exemplo. É nesse sentido que a pessoa teria uma compreensão mais ampla frente às outras; ela as compreende porque já se sentiu exatamente assim no passado e conseguiria entender os outros em suas próprias modalidades de ser, buscando ser capaz de acomodar essa "variedade". Essa atitude de compreensão do "outro", então, seria o que distingue o "sábio" do "ignorante".

\section{Considerações finais}

Weber (1958, p. 119) descreve dois princípios característicos do racionalismo indiano: acredita-se que cada ato eticamente relevante tem consequências no destino do ator, daí nenhuma consequência ficar "perdida" (a doutrina do karma) e se acredita que a ideia de compensação está ligada ao "destino social" do indivíduo na organização societal. O autor acrescenta que não poderia haver uma recompensa ou punição "eterna" para o indivíduo, pois isto sem dúvida seria totalmente "fora de 
Religare, ISSN: 19826605, v.16, n.2, dezembro de 2019, p.659-691

proporções aos atos finitos", ou seja, trata-se da ideia de que alguém pode permanecer no "paraíso" ou no “inferno" apenas por um período limitado (1958, p. 120). É com este entendimento da teoria do karma que Weber (1993, p. 145) afirma que o que parece como sofrimento injusto na vida de uma pessoa deve ser entendido como reparação pelas ações em vidas passadas, já que cada indivíduo cria seu próprio destino exclusivamente, e no sentido estrito da palavra.

Ao observar o ethos e estilo de vida do grupo pesquisado, compreendi o ideal vedântico como a contínua tentativa de ser um yogi, isto é, alguém que não se deixa levar por um padrão de reação, que tenta segurar os impulsos e desejos em sua mente, aceitando o que a ordem cósmica trás a ele, e que passou por um processo de questionamento ao entender os erros e situações como oportunidades para amadurecer. Um aspecto importante, para os vedantinos, é a transformação por que passam ao vivenciar o ensinamento, que não deve ser entendida como uma mudança física, mas de visão de mundo - uma visão das situações que proporcionaria uma base para superar o sofrimento.

Além disso, o sofrimento, da perspectiva dos vedantinos, é considerado fruto da identificação com os pensamentos de julgamentos, projeções, sentimentos e emoções. Dominar a mente, para eles, é entendido como não se associar a esses pensamentos a fim de enxergar claramente o "Eu" que é livre, ou além, da mente, e que é a base do pensamento. Não se associando à mente, há a permanência no Eu. $\mathrm{O}$ "problema" é que a mente funciona através de nomes e formas e não consegue identificar aquilo que é livre de qualquer tipo de qualidade. Nesse sentido, através da meditação, existiria uma percepção de que a pessoa seria livre do corpo e da mente.

Como ressaltado, esses ensinamentos não devem ser apenas percepções "mentais", mas ser incorporados e vivenciados, o que, portanto, influencia a maneira como os vedantinos passam a construir suas visões de mundo. Essa 
Religare, ISSN: 19826605, v.16, n.2, dezembro de 2019, p.659-691

assimilação está baseada na crença de não importar onde nem o que estejam fazendo, mas o fundamental é a maneira como pensam a respeito de suas ações, o que torna essa religiosidade tanto racional como "fundamentalmente cultural" (Lipner 1994).

Dumont (1992, p. 325) explica que o renunciante deixou o mundo para trás a fim de se dedicar à sua própria liberação, isto é, ele "depende apenas de si mesmo, está só" e, desse modo, viu-se de repente "dotado de uma individualidade, incômoda sem dúvida, a qual ele deve transcender ou extinguir. Seu pensamento é o de um indivíduo. É esse traço essencial que o opõe ao homem-no-mundo e o aproxima, embora o distinga, do pensador ocidental". Segundo o antropólogo (1992, p. 326), o renunciante não nega propriamente a religião do "homem-no-mundo", o que abre a possibilidade da "agregação" de sua religião no sentido de sua disciplina se acrescentar à religião do "homem-no-mundo", quer dizer, "à religião de grupo se superpõe uma religião individual, fundada numa escolha". Sugiro que seja essa característica da religiosidade não ser institucionalizada, mas individual, fundada em uma escolha, o que atrai os pesquisados e, talvez, muitos adeptos da Nova Era. ${ }^{22}$

Para concluir, Dumont (1992) lembra que o renunciante - algo muito importante para o nosso propósito - transformou a renúncia em um ato interno: a renúncia passa a estar "dentro" da pessoa e não na ação de praticar austeridades. Esse tipo de renúncia envolve, portanto, a tentativa constante de se levar uma vida de yoga. É a partir desses pressupostos que a meta de se tornar um yogi deve ser entendida. Essa meta é psicologicamente sentida como uma oposição ao mundo, não

\footnotetext{
${ }^{22}$ Campbell (2013, p. 77-78) entende que se existe uma única visão de mundo discernível que engloba o movimento Nova Era é a crença de que a realidade última é espiritual e sua suposição básica seria a existência de um poder, contido em todas as coisas e presente em todo o universo (até em elementos como terra, vento, fogo, água e também nos planetas e estrelas), geralmente assumido como sendo uma única força ou espírito que se manifesta de formas múltiplas e diferenciadas; mais à frente, Campbell $(2013$, p. 83) conclui sua teoria revelando que não se trata de uma teodiceia social no sentido de unir indivíduos e gerações em rituais ou instituições comuns, mas de uma teodiceia intensamente individualista que une o self diretamente ao cosmos.
} 
Religare, ISSN: 19826605, v.16, n.2, dezembro de 2019, p.659-691

no sentido de um abandono mas, afirma Weber (1993, p. 169), como uma repetida vitória sobre novas tentações às quais se está sujeito a combater ativamente, a todo o momento. Como observado, os vedantinos buscam e idealizam se tornar yogis através do constante exercício de observação de seus sentidos, impulsos e desejos, mantendo a mente sempre no "Eu" a fim de conquistar um tipo de mente consciente de sua própria natureza, que é a liberação.

\section{Referências}

BASTOS, Cecilia, Em busca de espiritualidade na Índia: os significados de uma moderna peregrinação. Curitiba: Editora Prismas, 2016a.

. Uma espiritualidade "hindu" no Ocidente: a influência do Vedanta no contexto Nova Era. Ciências Sociais e Religião, n. 24, p. 33-53, 2016b.

2016c.

A construção social de uma ideia de Índia. Novos Olhares, v. 5, n. 2, p. 98-111,

. Perspectivas antropológicas sobre o turismo religioso: atravessando as fronteiras do turismo e da peregrinação. Debates do NER, v. 18, n. 31, p. 307-330, 2017a.

- A busca espiritual de viajantes à Índia: filosofia e prática de um estilo de vida. Revista Brasileira de História das Religiões, v. 09, n. 27, p. 229-255, 2017b.

. Em busca do sentido da vida: a perspectivas de estudantes de Vedanta sobre uma "vida de yoga". Religião e Sociedade, Rio de Janeiro, v. 38, n. 3, p. 218-238, 2018. BHAWUK, Dharm. Anchoring cognition, emotion and behavior in desire: a model from the Bhagavad-Gita. In: RAO, PARANJPE, \& DALAL (Orgs.) Handbook of Indian psychology. New Delhi: Cambridge University Press, 2008. p. 390-413.

CAMPBELL, Colin. A New Age theodicy for a new age. In: HEELAS, MARTIN \& WOODHEAD (Orgs.) Peter Berger and the study of religion. New York: Routledge, 2013. p. 76-87.

DALAL, Neil. Advaita vedanta and recent debates over mystical experience. South Asia Graduate Research Journal, v. 14, p. 37-62, 2005.

DASGUPTA, Surendranath. A history of Indian Philosophy, vol. I. Cambridge: Cambridge University Press, 2004.

. A history of Indian Philosophy. Cambridge: Cambridge University Press, 2009.

II v.

DUMONT, Louis. Religion, politics and history in India: collected papers in Indian sociology. Paris: Mouton, 1970. 
Religare, ISSN: 19826605, v.16, n.2, dezembro de 2019, p.659-691

. O individualismo: uma perspectiva antropológica da ideologia moderna. Rio de Janeiro: Rocco, 1985.

. Homo hierarchicus: o sistema de castas e suas implicações. São Paulo: Editora da Universidade de São Paulo, 1992.

ELIADE, Mircea. Yoga: imortalidade e liberdade. São Paulo: Palas Athena, 1996.

HEELAS, Paul. Spiritualities of life: New age romanticism and consumptive capitalism. Oxford: Blackwell Publishing, 2008.

LIPNER, Julius. Hindus: their religious beliefs and practices. London: Routledge, 1994.

NERY, Paulo. Relatos de viagem e construção da pessoa em Guimarães Rosa: o deslocamento como valor. Brasília: Universidade de Brasília, 2003. 331 v. (Série antropologia).

RYFF, Carol. Happiness is everything, or is it? Explorations on the meaning of psychological well-being. Journal of Personality and Social Psychology, v. 57, n. 6, p. 1989, 1069-1081.

ROUNTREE, Kathryn. Performing the divine: neo-pagan pilgrimages and embodiment at sacred sites. Body \& Society. v. 12, n. 4, p. 95-115, 2006.

RYAN, Richard, HUTA, Veronika \& DECI, Edward. Living Well: A Self- Determination Theory Perspective on Eudaimonia. Journal of Happiness Studies. v. 9, 2008. p. 139-170.

SCHECHNER, Richard. Pontos de contato revisitados. In: DAWSEY, J. et al. (Orgs.) Antropologia e Performance. São Paulo: Terceiro Nome, 2013. p. 23-66.

TURNER, Victor. O processo ritual: estrutura e anti-estrutura. Petrópolis: Vozes, 1974. WEBER, Max. The religion of India. The sociology of Hinduism and Buddhism. Glencoe, Illinois: Free Press, 1958. . The sociology of religion. Boston: Beacon Press, 1993.

ZIMMER, Heinrich. Filosofias de la India. Buenos Aires: EUDEBA, 1979. (Editorial Universitaria de Buenos Aires).

Recebido em 12-06-2019. Aprovado em 08-08-2019. 